University of Massachusetts Amherst

ScholarWorks@UMass Amherst

2000

\title{
Chemical speciation influences comparative activity of selenium-enriched garlic and yeast in mammary cancer prevention
}

C Ip

M Birringer

E Block

M Kotrebai

JF Tyson

See next page for additional authors

Follow this and additional works at: https://scholarworks.umass.edu/chem_faculty_pubs

\section{Recommended Citation}

Ip, C; Birringer, M; Block, E; Kotrebai, M; Tyson, JF; Uden, PC; and Lisk, DJ, "Chemical speciation influences comparative activity of selenium-enriched garlic and yeast in mammary cancer prevention" (2000). JOURNAL OF AGRICULTURAL AND FOOD CHEMISTRY. 1046.

Retrieved from https://scholarworks.umass.edu/chem_faculty_pubs/1046 
Authors

C Ip, M Birringer, E Block, M Kotrebai, JF Tyson, PC Uden, and DJ Lisk 


\title{
Chemical Speciation Influences Comparative Activity of Selenium-E nriched Garlic and Yeast in Mammary Cancer Prevention
}

\author{
Clement I p,*,† Marc Birringer,, Eric Block, $¥$ Mihály Kotrebai, $\$$ J ulian F. Tyson, $\$$ \\ Peter C. Uden, $\$$ and Donald J . Lisk\#
}

\begin{abstract}
Department of Experimental Pathology, Roswell Park Cancer Institute, Buffalo, New York 14263; Department of Chemistry, SUNY-Albany, Albany, New York 12222; Department of Chemistry, University of Massachusetts, Amherst, Massachusetts 01003; and Department of Fruit and Vegetable Science, Cornell University, Ithaca, New York 14853
\end{abstract}

\begin{abstract}
A recent human intervention trial showed that daily supplementation with selenized yeast (Seyeast) led to a decrease in the overall cancer morbidity and mortality by nearly $50 \%$; past research has also demonstrated that selenized garlic (Segarlic) is very effective in mammary cancer chemoprevention in the rat model. The goal of this study was to compare certain biological activities of Segarlic and Se-yeast and to elucidate the differences based on the chemical forms of selenium found in these two natural products. Characterization of organic selenium compounds in yeast (1922 $\mu \mathrm{g} / \mathrm{g} \mathrm{Se}$ ) and garlic ( $296 \mu \mathrm{g} / \mathrm{g} \mathrm{Se}$ ) was carried out by high-performance liquid chromatography with inductively coupled plasma mass spectrometry or with electrospray mass spectrometry. Analytical speciation studies showed that the bulk of the selenium in Se-garlic and Se-yeast is in the form of $\gamma$-glutamyl-Semethylselenocysteine (73\%) and selenomethionine (85\%), respectively. The above methodology has the sensitivity and capability to account for $>90 \%$ of total selenium. In the rat feeding studies, supplementation of Se-garlic in the diet at different levels consistently caused a lower total tissue selenium accumulation when compared to Se-yeast. On the other hand, Se-garlic was significantly more effective in suppressing the development of premalignant lesions and the formation of adenocarcinomas in the mammary gland of carcinogen-treated rats. Given the present finding on the identity of selenomethionine and $\gamma$-glutamyl-Se-methylsel enocysteine as the major form of selenium in Se-yeast and Se-garlic, respectively, the metabolism of these two compounds is discussed in an attempt to elucidate how their disposition in tissues might account for the differences in cancer chemopreventive activity.
\end{abstract}

Keywords: Selenized natural product; garlic; yeast; chemical speciation of sel enium; selenium cancer prevention

\section{INTRODUCTION}

The most exciting news in selenium and cancer prevention research in recent years is the finding by Clark et al. (1996) that supplementation of freeliving people with selenized brewer's yeast is capable of decreasing the overall cancer morbidity and mortality by nearly $50 \%$. The study was a double-blind, randomized, placebo-controlled trial involving 1312 patients (mostly men) who were recruited initially because of a history of basal cell or squamous cell carcinoma of the skin. Individuals in the treatment arm were given 200 $\mu \mathrm{g}$ of Se per day (average daily intake in the United States is $\sim 100 \mu \mathrm{g}$ ) for a mean of 4.5 years. After a total follow-up of 8271 person-years, selenium treatment did not significantly affect the incidence of these nonmelanoma skin lesions. However, patients receiving the Se-

* Address correspondence to this author at the Department of Experimental Pathology, Roswell Park Cancer Institute, EIm and Carlton St., Buffal o, NY 14263 [tel ephone (716) 8458875; fax (716) 845-8100; e-mail Clement.I p@roswellpark.org].

${ }^{\dagger}$ Roswell Park Cancer Institute.

‡ SUNY-Albany.

$\S$ University of Massachusetts.

*Cornell University. yeast supplement showed a much lower prevalence of developing and dying from lung, colon, or prostate cancer (RR varied from 0.66 to 0.33 ). Although these beneficial effects of sel enium require independent confirmation with an appropriate design, the above study demonstrated that selenium supplementation represents a safe and viable way of achieving significant cancer protection.

The intervention trial of Clark et al. (1996) is a classic example of "targeted chemoprevention" in which a particular substance is given to high-risk individuals for the purpose of reducing cancer morbidity. There is a second concept of chemoprevention which is ai med at providing cancer protective chemicals to large segments of the population who are not at an increased risk because of known exposure to carcinogens, genetic predisposition, or prior diagnosis of malignancy (Wattenberg, 1992). This plan requires a wide distribution method, and an expeditious way of delivering these protective agents is through foods.

It is almost impossible to increase selenium intake by eating certain types of food because most common foods have a very low selenium content (Morris and Levander, 1970). Stimulated by the knowledge that plants convert inorganic selenium in soil to organic 
selenium compounds following the sulfur assimilatory pathway (Shrift, 1973), I p and co-workers were able to enrich garlic with selenium by fertilizing the crop with water-soluble selenate and sel enite salts (I p et al., 1992). By controlling the intensity and frequency of selenium fertilization, it is possible to cultivate Se-garlic enriched with 100-1355 $\mu \mathrm{g} / \mathrm{g}$ Se dry weight (I p and Lisk, 1995). As a point of reference, natural garlic sold in the grocery stores contains $<0.05 \mu \mathrm{g} / \mathrm{g}$ Se. After harvest and processing, the Segarlic was lyophilized and milled to a powder for feeding to laboratory animals for characterization of its cancer chemopreventive activity (I p and Lisk, 1994, 1995, 1997; Ip et al., 1996).

New methodologies of high-performance liquid chromatography with inductively coupled plasma mass spectrometry (HPLC-ICP-MS) and with electrospray mass spectrometry (ESI-MS) as well as gas chromatography with atomic emission detection (GC-AED) have recently been used to characterize a variety of organic selenium compounds from natural sources at levels as low as 20 ng/mL Se (Cai et al., 1995; Ge et al., 1996; Bird et al., 1997a,b; Uden et al., 1998; Kotrebai et al., 1999; Casiot et al., 1999). Our plan was to carry out parallel analytical and biological studies on the same batch of Se-garlic and Se-yeast so that the information from selenium-enriched foods can be integrated and interpreted in a meaningful manner.

\section{MATERIALS AND METHODS}

Se-Yeast and Se-Garlic. The high-selenium brewer's yeast was obtained from Nutrition 21, San Diego, CA. The material, which was provided in a powder form ( $95 \%$ through 60 mesh), contained $1922 \mu \mathrm{g} / \mathrm{g}$ Se on a dry weight basis. The Se-garlic, produced by inorganic selenium salt fertilization as described previously (Ip et al., 1992), contained $296 \mu \mathrm{g} / \mathrm{g}$ Se. Total selenium analysis was determined by using the fluorometric method of Olson et al. (1975) or by ICP-MS (Uden et al., 1998; Kotrebai et al., 1999).

Instrumentation. An inductively coupled plasma mass spectrometer (ICP-MS) (Elan 5000, Perkin-EImer Sciex, Thornhill, ON, Canada) served as the detector for HPLC. Samples were introduced by a Meinhard nebulizer with a spray chamber containing an impact bead. The ICP-MS parameters were as described elsewhere (Kotrebai et al., 1999). The chromatographic system consisted of a pump (SP8810, SpectraPhysics, San J ose, CA) and a $5 \mu \mathrm{m}$ Symmetry Shield RP8 column (3.9 mm $\times 15 \mathrm{~cm}$; Waters Corp., Milford, MA). The column was connected to the nebulizer with PEEK tubing (30 $\mathrm{cm} \times 0.25 \mathrm{~mm}$ i.d.). The mobile phase composition was 99:1 $(\mathrm{v} / \mathrm{v})$ water/methanol with $0.1 \%$ trifluoroacetic acid or $0.1 \%$ heptafluorobutanoic acid. The mobile phase flow rate was typically $1.0 \mathrm{~mL} / \mathrm{min}$, and the sample injection volume was $20 \mu \mathrm{L}$.

A Bruker-Hewlett-Packard Esquire LC mass spectrometer (Bruker-Franzen Analytik GmbH, Bremen, Germany) was used for the molecular mass spectral studies. For HPLC-MS analysis, the $1 \mathrm{~mL} / \mathrm{min}$ column output was split in a 1:5 ratio with a T flow splitter. The col umn was connected to the ESI source with PEEK tubing $(8 \mathrm{~cm} \times 0.25 \mathrm{~mm}$ i.d.). Mass calibration and optimization were performed daily.

Chemicals. Barnstead E-pure $18 \mathrm{Mohm}$ water (Boston, MA), hydrochl oric acid (purified by sub-boiling), trifluoroacetic acid (Aldrich, Milwaukee, WI), and methanol (HPLC grade) were used. DL-Selenomethionine and Protease XIV were obtained from Sigma (St. Louis, MO). SeAdenosyl-DL-selenohomocysteine and $\gamma$-glutamyl-Semethyl-L-sel enocysteine were synthesized in-house (E. Block et al., unpubl ished data). Stock solutions of selenoamino acids were prepared in $0.2 \mathrm{M} \mathrm{HCl}$. All solutions were stored in the dark at $0-4{ }^{\circ} \mathrm{C}$.

Sample Preparation. The enzymatic and hot water extractions of Se-garlic and Se-yeast followed the procedures reported earlier (Uden et al., 1998) and therefore are only briefly summarized here. For the hot water extraction, $5 \mathrm{~mL}$ of distilled deionized water was added to $0.2 \mathrm{~g}$ of sample in a 15- $\mathrm{mL}$ centrifuge tube, and the tube was placed in a doubleboiling water bath for an hour. The mixture was shaken well every $15 \mathrm{~min}$. For the enzymatic extraction, $5 \mathrm{~mL}$ of distilled deionized water was added to $0.2 \mathrm{~g}$ of sample and $0.02 \mathrm{~g}$ of Protease XIV enzyme in a $15-\mathrm{mL}$ centrifuge tube and shaken for $24 \mathrm{~h}$ at room temperature. For the preparation of concentrated extracts, the original sample-to-water ratio $(0.2 \mathrm{~g} / 5 \mathrm{~mL})$ was increased 5-fold. After the extraction, the samples were centrifuged and filtered.

Design of in Vivo Experiments in Rats. The biological activities of Se-yeast and Se-garlic were evaluated in rats with the use of three separate endpoints: tissue selenium accumulation, reduction of premalignant lesions in the mammary gland, and mammary cancer prevention bioassay. Pathogen-free female Sprague-Dawley rats were purchased from Charles River Breeding Laboratories (Wilmington, NC) at 45 days of age. They were fed the AIN-76A basal diet (Report of the American I nstitute of Nutrition, 1977) for several days to acclimatize them to the powder ration. This basal diet contained $0.1 \mu \mathrm{g} / \mathrm{g}$ Se as sodium selenite. At $\sim 50$ days of age, the animals were entered into different experimental protocols as described below.

For the tissue selenium accumulation study, rats were given either Se-garlic or Se-yeast, supplemented to the basal diet at a final concentration of 1,2 , or $3 \mu \mathrm{g} / \mathrm{g}$ Se ( $n=6 / \mathrm{group})$. The feeding continued for 6 weeks, at which point the animals were sacrificed. Liver, kidney, mammary gland, skeletal musde, and plasma were collected at necropsy. The samples were frozen immediately in liquid nitrogen and stored at $-80^{\circ} \mathrm{C}$ until ready for analysis of total selenium (Olson et al., 1975).

For the mammary gland premalignant lesion study, rats were injected i.p. with methylnitrosourea (MNU) at a dose of $50 \mathrm{mg} / \mathrm{kg}$ of body weight. I mmediately after carcinogen administration, animals were divided into three groups ( $n=6$ rats/group): control (fed basal diet containing $0.1 \mu \mathrm{g} / \mathrm{g} \mathrm{Se}$ ), Segarlic (at $3 \mu \mathrm{g} / \mathrm{g} \mathrm{Se}$ ), and Seyeast (at $3 \mu \mathrm{g} / \mathrm{g} \mathrm{Se}$ ). Animals were sacrificed at 6 weeks after selenium supplementation. The abdominal-inguinal mammary gland chain was excised in one piece, fixed in $10 \%$ buffered formalin, and processed in a Tissue-Tek vacuum infiltration processor. After processing, it was divided into six segments and embedded in paraffin blocks. Ribbons of 5- $\mu \mathrm{m}$ thickness were cut from each block and placed on slides that had been treated with 3-aminopropyltriethoxysilane. Every 10th section was heat immobilized, deparaffinized in xylene, rehydrated in descending grades of ethanol, and stained with hematoxylin and eosin. These $H \& E$ slides were examined under the microscope for the appearance of premalignant intraductal proliferation (IDP) lesions using the criteria delineated by Russo et al. (1982). Once an IDP lesion was found, the in-between slides were similarly stained to confirm the histology. The size of each lesion could thus be estimated operationally by the number of serial sections showing the pathology. The total IDP count data were analyzed by the chi square test using the Poisson regression model (McCullagh and Nelder, 1989).

Two mammary cancer prevention bioassays were carried out, one with the MNU model and the other with the dimethyl benz[a]anthracene (DMBA) model. Rats in each experiment were given a dose of MNU (50 mg/kg of body wt) i.p. or DMBA (50 mg/kg of body wt) i.g. at $\sim 50$ days of age for the induction of mammary tumors. They were then fed the Segarlic- or Se-yeast-containing diet at a level of $3 \mu \mathrm{g} / \mathrm{g} \mathrm{Se}$. Control rats continued to receive the basal diet containing 0.1 $\mu \mathrm{g} / \mathrm{g}$ Se. All animals were pal pated for mammary gland tumors once a week. The experiment was continued for 24 weeks before termination. By this time, the development of palpable tumors had plateaued for several weeks across all groups. At necropsy, all tumors were excised and fixed for histological evaluation. Only confirmed adenocarcinomas are reported in the results. Tumor incidences at the final time point were compared by chi-square analysis, and thetotal tumor yield 

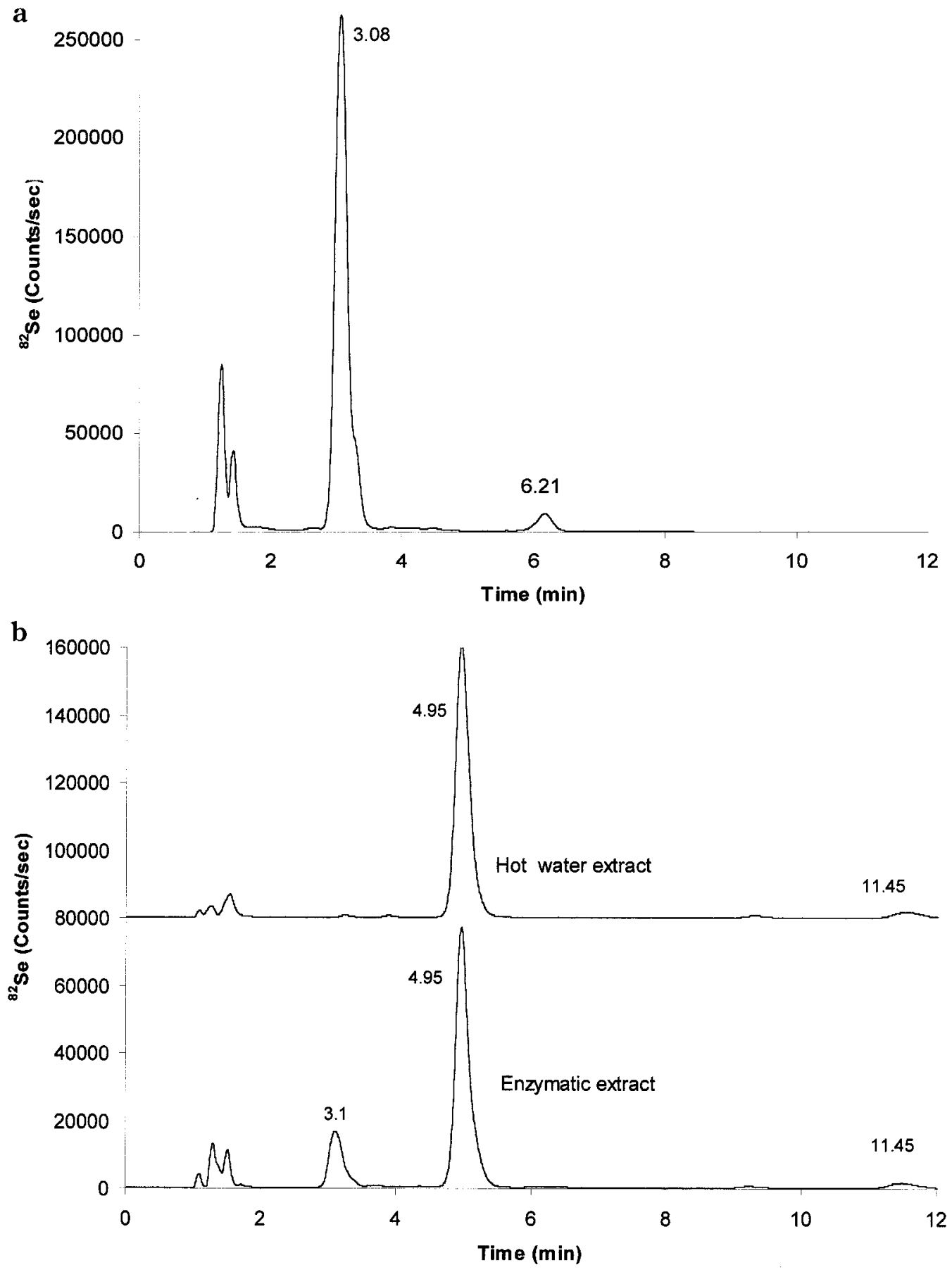

Figure 1. (A) HPLC-ICP-MS chromatogram, using $0.1 \%$ trifluoroacetic acid ion pairing agent, of the enzymatic extract of seleniumenriched yeast containing $1922 \mu \mathrm{g} / \mathrm{g}$ total selenium; (B) HPLC-ICP-MS chromatograms, using $0.1 \%$ trifluoroacetic acid, of the hot water extract (top) and the enzymatic extract (bottom) of selenium-enriched garlic containing $296 \mu \mathrm{g} / \mathrm{g}$ total selenium.

was compared by frequency distribution analysis as described previously (Horvath and Ip, 1983).

\section{RESULTS}

HPLC-ICP-MS Analysis. On-line HPLC-ICP-MS chromatograms, using $0.1 \%$ trifluoroacetic acid as ionpairing agent, of enzymatic extract of Seyeast and water extract of Segarlic are shown in parts $a$ and $b$, respectively, of Figure 1 ( $0.2 \mathrm{~g} / 5 \mathrm{~mL}$ of sample extract). The identities of the peaks eluting at 3.08 and $6.21 \mathrm{~min}$ (Figure $1 \mathrm{a}$ ) and at $4.95 \mathrm{~min}$ (Figure 1b) were first established by spiking the samples with the appropriate standards. The peaks were identified as selenomethionine, Seadenosylselenohomocysteine, and $\gamma$-glutamyl-Se methylselenocysteine, respectively. The peak at 11.45 min (F igure 1b) could not be matched by retention time against any available standard.

Comparison of a yeast water extract (not shown) with Figure la showed the absence of the major selenomethionine peak, suggesting that it is immobilized, perhaps in proteins; Seadenosylselenohomocysteine appeared as the major sel eni um compound. The extraction efficiency and column recovery values of selenium for the enzymatic extracts of yeast were $80-90 \%$, whereas the hot water extraction efficiency was only 10\% (Uden et al., 1998; Kotrebai et al., 1999). The two identified compounds account for $\sim 82 \%$ of the total selenium in compounds eluting from the enzymatic extract. 


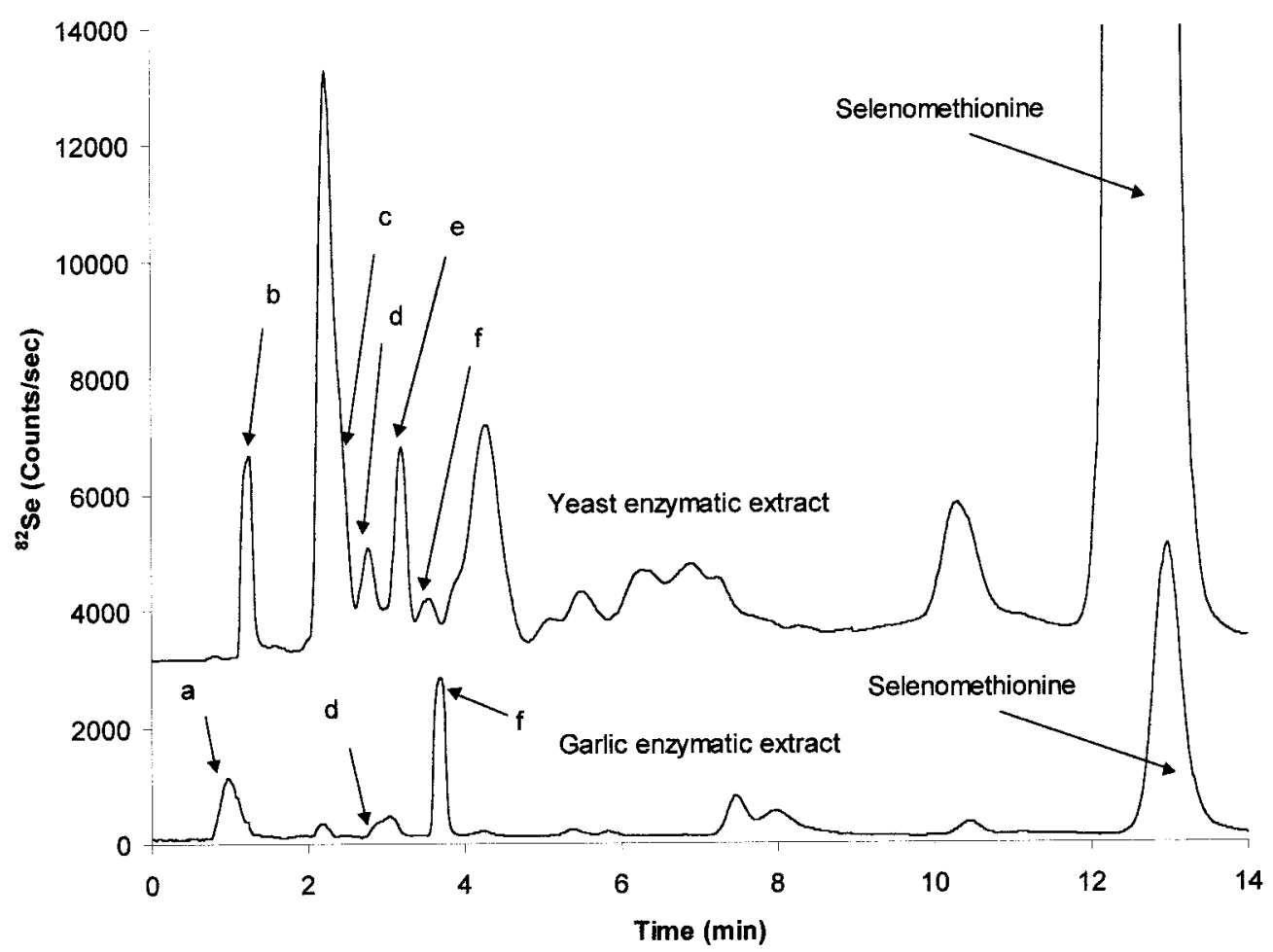

Figure 2. HPLC-ICP-MS chromatograms of the hot water extract (top) and the enzymatic extract (bottom) of sel enium-enriched garlic containing $296 \mu \mathrm{g} / \mathrm{g}$ total selenium.

Comparison of the garlic powder's water extract with its enzymatic extract (Figure $1 b$ ) shows no major difference in the $\gamma$-glutamyl-Semethylsel enocysteine peak areas, indicating that it is not immobilized into proteins. As observed in the case of yeast, selenomethionine (peak at $3.1 \mathrm{~min}$ ) was effectively extracted only by the enzymatic process. For garlic powder, the hot water extraction column recovery values were 80$90 \%, \gamma$-glutamyl-Semethylsel enocysteine accounting for $85 \%$ of the total selenium compounds eluted. With enzymatic extraction, the efficiency approached $100 \%$, with selenomethionine and $\gamma$-glutamyl-Se-methylselenocysteine together accounting for $\sim 86 \%$ of the total selenium species eluted.

The separation achieved by the use of trifluoroacetic acid (Figure $1 a, b)$ was not of adequate resolution to identify the early eluting peaks in the chromatogram. To identify the compounds in that region, heptafluorobutanoic acid, a much stronger ion-pairing agent, was used. This separation is demonstrated in Figure 2. The identifications of (a) selenate, (b) selenite, (c) selenolanthionine, (d) selenocystine, (e) selenocystathionine, and (f) Semethylsel enocysteine were made by spiking the samples with the appropriate standards. As noted above, the extraction efficiency from yeast was estimated to be between 80 and $90 \%$ based on total selenium content, whereas that from garlic was close to $100 \%$ on the same basis. The independence of ICPMS response for selenium-82 with respect to molecular structure enables total chromatographic peak area measurements to be used for these calculations with confidence. The percentage composition of the selenium content eluted from the col umn, taking into account the foregoing extraction efficiency, is reported in Table 1.

HPLC-ESI-MS Analysis. All analyses were carried out on-line, to preclude sample decomposition during the preconcentration procedure. Figure 3 shows the overlaid single ion chromatograms (SIC) of selenom-
Table 1. Percent Composition of Identified Selenium Species Based upon Selenium Content of Selenized Garlic and Yeast

\begin{tabular}{|c|c|c|}
\hline & $\begin{array}{l}296 \mu \mathrm{g} / \mathrm{g} \mathrm{Se}- \\
\text { garlic (\%) }\end{array}$ & $\begin{array}{l}1922 \mu \mathrm{g} / \mathrm{g} \mathrm{Se} \\
\text { yeast (\%) }\end{array}$ \\
\hline (a) selenate & 2 & \\
\hline (b) selenite & & 1 \\
\hline (c) selenolanthionine & & 1.5 \\
\hline (d) selenocystine & 0.5 & 0.5 \\
\hline (e) selenocystathionine & 0.5 & 1 \\
\hline (f) Se-methylselenocysteine & 3 & 0.5 \\
\hline (g) selenomethionine & 13 & 85 \\
\hline $\begin{array}{l}\text { (h) } \gamma \text {-glutamyl-Se-methylseleno- } \\
\text { cysteine }\end{array}$ & 73 & 0.5 \\
\hline (i) Seadenosyl selenohomocysteine & & 3 \\
\hline (j) $\gamma$-glutamyl-selenomethionine & 4 & \\
\hline percentage sum of eluted seleniuma & 96 & 93 \\
\hline
\end{tabular}

a Percentage sum is based on total eluted selenium by HPLCICP-MS, calculated from peak area measured at ${ }^{82} \mathrm{Se}$.

ethionine (3.41 $\mathrm{min}), \gamma$-glutamyl-Semethylsel enocysteine (5.07 $\mathrm{min})$, and Seadenosylselenohomocysteine (6.39 $\mathrm{min}$ ) at selenium concentrations of 50,20 , and 10 $\mu \mathrm{g} / \mathrm{mL}$, respectively. Separate chromatograms were run to obtain the best combination of response and peak shapes for the different levels of selenium in the three components. The selenomethionine has a mol ecular ion $M+1$ at 198 with a loss of 17 , which is attributed to ammonia, producing a fragment ion at $\mathrm{m} / \mathrm{z} 181$. The $\mathrm{M}$ +1 values for $\gamma$-glutamyl-Se-methylselenocysteine and Seadenosylselenohomocysteine are 313 and 433, respectively. The distinctive selenium isotopic pattern $\left[{ }^{74} \mathrm{Se}(1 \%),{ }^{76} \mathrm{Se}(9 \%),{ }^{77} \mathrm{Se}(8 \%),{ }^{78} \mathrm{Se}(24 \%),{ }^{80} \mathrm{Se}(50 \%)\right.$, $\left.{ }^{82} \mathrm{Se}(9 \%)\right]$ is clearly seen in each case.

The SIC of $\mathrm{m} / \mathrm{z} 313$ (5.11 $\mathrm{min}$ ) and $\mathrm{m} / \mathrm{z} 327$ (10.12 min) from "dilute" $(0.2 \mathrm{~g} / 5 \mathrm{~mL})$ and "concentrated" $(1 \mathrm{~g} / 5 \mathrm{~mL})$ hot water extracts of garlic, respectively, are shown in Figure 4. The "concentrated" extracts showed a retenti on time decrease as seen for Figure 2 (11.45 min) and Figure 4 (10.12 $\mathrm{min}$ ) for the same compound, due to 


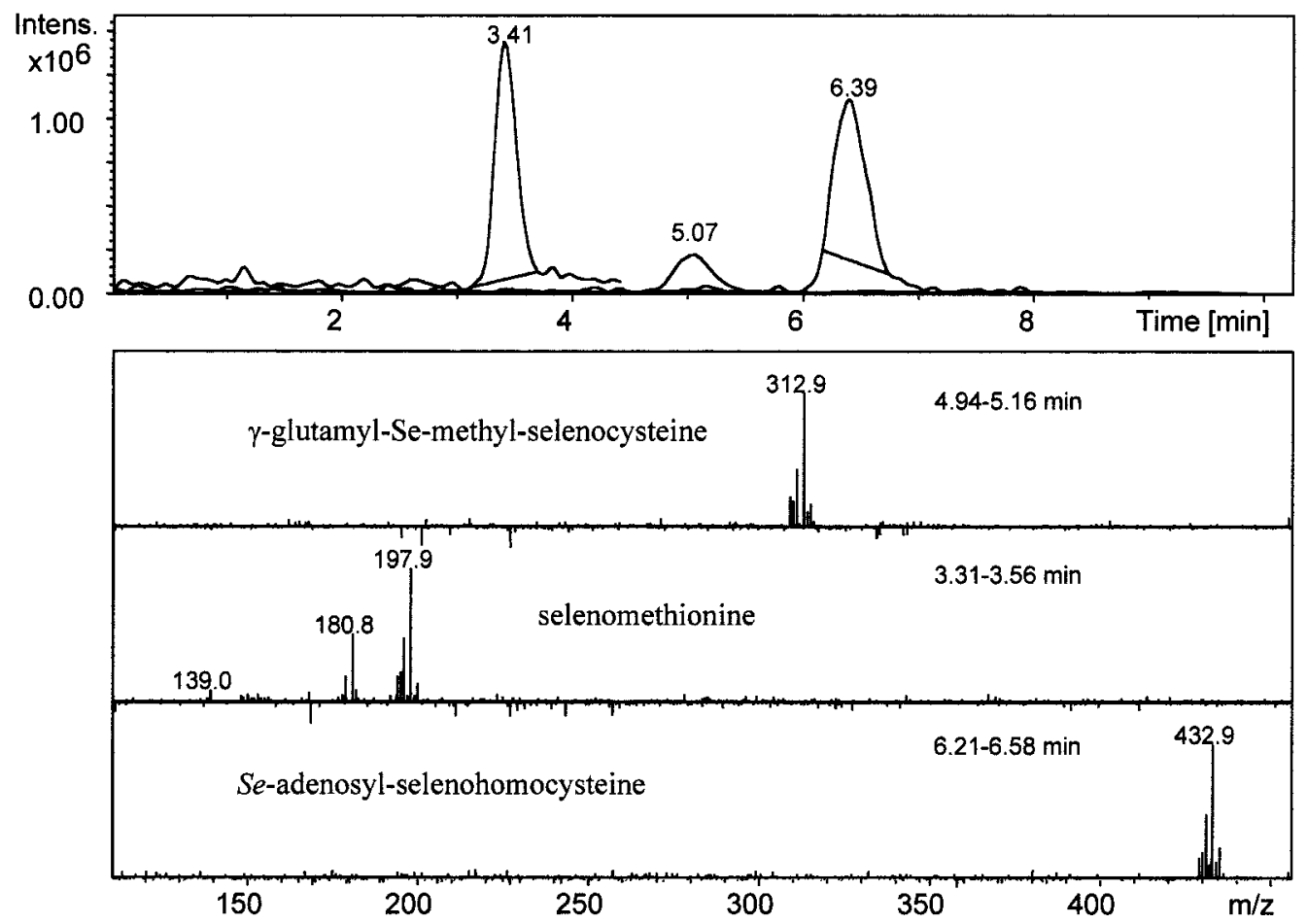

Figure 3. HPLC-ESI-MS SIC of DL-selenomethionine (3.41 min, $\mathrm{m} / \mathrm{z} 198), \gamma$-glutamyl-Semethylselenocysteine (5.07 min, $\mathrm{m} / \mathrm{z}$ 313), and Se-adenosylselenohomocysteine (6.39 $\mathrm{min}, \mathrm{m} / \mathrm{z} 433$ ) with concentrations of 50, 20, and $10 \mu \mathrm{g} / \mathrm{mL}$ selenium, respectively, recorded in three separate injections and overlaid in one chromatogram.

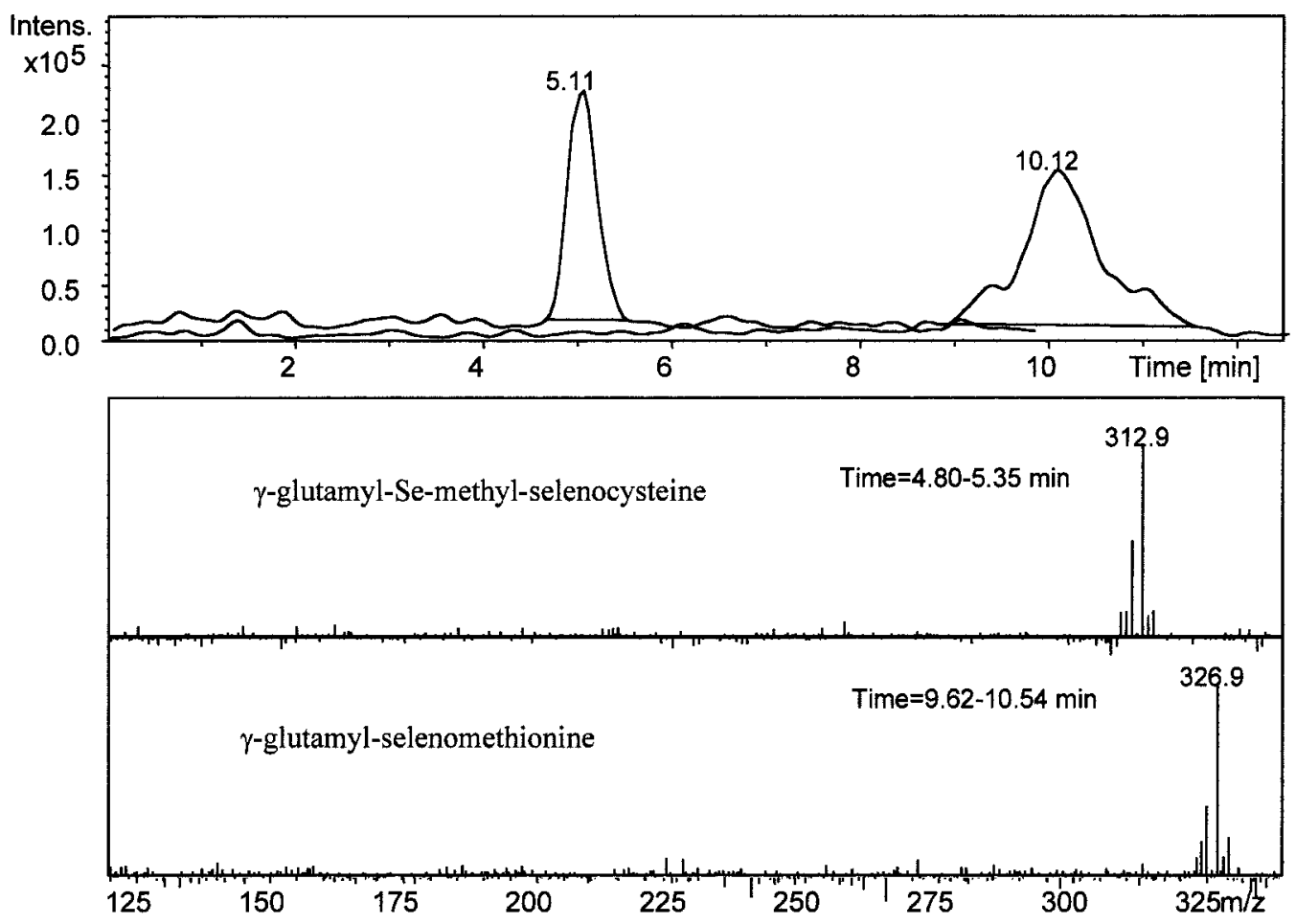

Figure 4. HPLC-ESI-MS SIC chromatograms of m/z 313 (5.11 min) and 327 (10.12 min) ions with their spectra from the water extract of selenium-enriched garlic containing $296 \mu \mathrm{g} / \mathrm{g}$ total selenium.

overloading of the column. The same effect was seen when the injection volume of the dilute extract was increased 5 -fold from 20 to $100 \mu \mathrm{L}$. The mass spectrum of the 5.11 min peak confirms the identification of this peak as $\gamma$-glutamyl-Semethyl selenocysteine. The peak at 10.12 min was tentatively identified as $\gamma$-glutamylselenomethionine on the basis of its molecular weight, the region where it elutes, and the fact that $\gamma$-glutamylmethionine occurs in garlic (Virtanen, 1965; Koch and
Lawson, 1996), but a standard to confirm its retention time is not yet available.

The SIC of m/z 198 (3.14 min) and m/z 433 (6.31 min) from the dilute enzymatic extract of Se-yeast appears in Figure 5. A similar mass spectrum is obtained for the peak eluting at $6.3 \mathrm{~min}$ from the hot water extract of the same sample. The mass spectra of the peaks at 3.14 and $6.31 \mathrm{~min}$ confirm their identity as selenomethionine and Se-adenosylsel enohomocysteine, respec- 


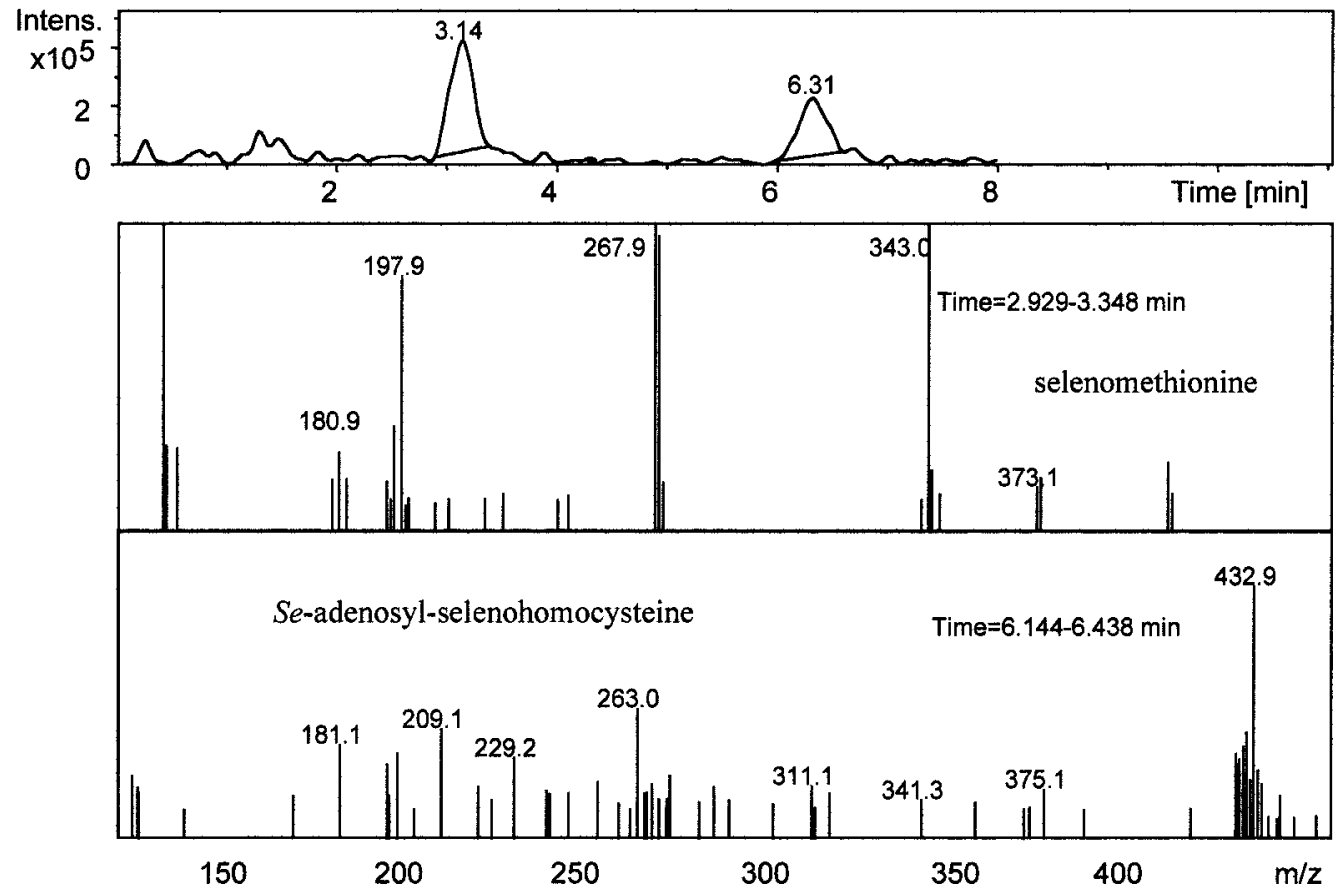

Figure 5. HPLC-ESI-MS SIC chromatograms of m/z 198 (3.14 min) and 433 (6.31 min) ions with their spectra from the enzyme extract of selenium-enriched yeast containing $1922 \mu \mathrm{g} / \mathrm{g}$ total selenium.

Table 2. Tissue Selenium Levels in Rats Fed Se-Garlic or Se-Yeast

\begin{tabular}{ccccccc}
\hline & \multirow{2}{*}{$\begin{array}{c}\text { dietary selenium } \\
\text { treatment }\end{array}$} & \multicolumn{4}{c}{ selenium concn $(\mu \mathrm{g} / \mathrm{g}$ or $\mathrm{mL})$} \\
\cline { 3 - 6 } & 0.1 & liver & kidney & mammary & muscle & plasma \\
\hline none & 1 & $4.1 \pm 0.22$ & $5.1 \pm 0.26$ & $0.12 \pm 0.01$ & $0.8 \pm 0.03$ & $0.42 \pm 0.02$ \\
Se-garlic & 2 & $5.1 \pm 0.38^{\mathrm{a}}$ & $6.1 \pm 0.41^{\mathrm{a}}$ & $0.14 \pm 0.01^{\mathrm{a}}$ & $1.0 \pm 0.02^{\mathrm{a}}$ & $0.51 \pm 0.03^{\mathrm{a}}$ \\
Se-garlic & 3 & $6.1 \pm 0.47^{\mathrm{b}}$ & $7.6 \pm 0.49^{\mathrm{b}}$ & $0.19 \pm 0.01^{\mathrm{b}}$ & $1.5 \pm 0.03^{\mathrm{b}}$ & $0.56 \pm 0.03^{\mathrm{b}}$ \\
Se-garlic & 1 & $7.3 \pm 0.60^{\mathrm{c}}$ & $8.7 \pm 0.66^{\mathrm{c}}$ & $0.20 \pm 0.02^{\mathrm{c}}$ & $1.8 \pm 0.07^{\mathrm{c}}$ & $0.65 \pm 0.04^{\mathrm{c}}$ \\
Se-yeast & 2 & $8.1 \pm 0.65^{\mathrm{a}}$ & $8.5 \pm 0.68^{\mathrm{a}}$ & $0.25 \pm 0.02^{\mathrm{a}}$ & $1.5 \pm 0.04^{\mathrm{a}}$ & $0.62 \pm 0.04^{\mathrm{a}}$ \\
Se-yeast & 3 & $13.4 \pm 0.98^{\mathrm{b}}$ & $13.3 \pm 0.96^{\mathrm{b}}$ & $0.31 \pm 0.02^{\mathrm{b}}$ & $2.5 \pm 0.11^{\mathrm{b}}$ & $0.83 \pm 0.06^{\mathrm{b}}$ \\
Se-yeast & $15.9 \pm 1.2^{\mathrm{c}}$ & $20.4 \pm 1.5^{\mathrm{c}}$ & $0.41 \pm 0.03^{\mathrm{c}}$ & $3.8 \pm 0.15^{\mathrm{c}}$ & $0.94 \pm 0.07^{\mathrm{c}}$
\end{tabular}

${ }^{a-c}$ The values from the Se-garlic and Se-yeast groups are significantly different from each other $(P<0.05)$.

tively, reinforcing the off-line identification of Seadenosylselenohomocysteine in the water extract of Seyeast (Casiot et al., 1999). The additional noted ions appearing in these spectra in comparison with the HPLC of the reference compounds in Figure 3 are due to non-sel enium-containing species coeluting or overlapping with the target analytes. These give rise to ESIMS spectra but are, of course, not seen in selenium selective HPLC-ICP-MS.

Evaluation of Biological Activities. Table 2 shows the data of total selenium accumulation in tissues of rats fed either Se-garlic or Se-yeast. Both supplements produced a dose-dependent el evation in selenium levels in all tissues examined. However, in every case, Se-yeast caused a significantly higher increase in total selenium as compared to Se-garlic when either one was supplemented in the range of $1-3 \mu \mathrm{g} / \mathrm{g}$ dietary selenium. For example, at the $3 \mu \mathrm{g} / \mathrm{g}$ Se dose, the concentrations of selenium in liver, kidney, mammary gland, skeletal muscle, and plasma were 54, 57, 51, 53, and 31\% less, respectively, in rats fed Segarlic than in those fed Seyeast. Thus, it is clear that Se-garlic at chemopreventive levels of intake results in only a modest change in tissue selenium.

The pathobiology of chemical carcinogenesis in the rat mammary gland has been well elucidated by the team of Russo and Russo (1982). Their work provided evidence that the terminal end buds are the primary sites for the induction of mammary carcinomas. Within 2-3 weeks after carcinogen dosing, enlargement of the terminal end bud, due to a localized piling up of intraductal cells, is detectable in histological sections. These transformed cells continue to proliferate until they gradually fill up the lumen of the duct. These premalignant "intraductal proliferations", or IDPs, are the precursors for the eventual development of palpable carcinomas. The total count of these IDP lesions in the abdominalinguinal mammary gland chain was quantified as described under Materials and Methods. The size of each lesion was also determined operationally by the number of serial sections showing the same pathology.

Table 3 shows the IDP lesion results from MNUtreated rats that were fed either Se-garlic or Se-yeast. The histology of the mammary gland sections was evaluated at 6 weeks after carcinogen administration. There were 40 IDPs found in a total of 6 rats in the control group, 17 in the Se-garlic group, and 29 in the Se-yeast group. These values are all significantly different from each other (refer to footnote of Table 3 for statistical comparisons). The lesions were categorized into four size classes with each containing $\leq 10,11-20$, 21-30, or 31-40 serial sections. To analyze the size class data, a repeated-measures option was added to the Poisson regression because most animals presented lesions in more than one size class. No significant differences were found by treatment within a size class, 
Table 3. Reduction in the Number of IDP Lesions by Se-Garlic or Se-Yeast in the Mammary Gland of Rats Given MNU

\begin{tabular}{|c|c|c|c|c|c|c|c|}
\hline \multirow[b]{2}{*}{ treatment } & \multirow{2}{*}{$\begin{array}{c}\text { dietary selenium } \\
(\mu \mathrm{g} / \mathrm{g})\end{array}$} & \multirow{2}{*}{$\begin{array}{l}\text { no. of } \\
\text { rats }\end{array}$} & \multicolumn{4}{|c|}{ size distribution of IDP lesions } & \multirow[b]{2}{*}{ total no. } \\
\hline & & & $\leq 10$ sections & 11-20 sections & $21-30$ sections & $31-40$ sections & \\
\hline none & 0.1 & 6 & 4 & 12 & 9 & 15 & 40 \\
\hline Se-garlic & 3 & 6 & 5 & 5 & 3 & 4 & $17^{a}$ \\
\hline Se-yeast & 3 & 6 & 5 & 8 & 6 & 10 & $29^{b}$ \\
\hline
\end{tabular}

${ }^{\text {a }} \mathrm{P}=0.005$, compared to the Se-yeast group. ${ }^{\mathrm{b}} \mathrm{P}=0.034$, compared to the control group.

Table 4. Mammary Cancer Prevention by Se-Garlic or Se-Yeast in the DMBA and MNU Models

\begin{tabular}{cccccc}
\hline model & $\begin{array}{c}\text { treat- } \\
\text { ment }\end{array}$ & $\begin{array}{c}\text { dietary } \\
\text { selenium } \\
(\mu \mathrm{g} / \mathrm{g})\end{array}$ & $\begin{array}{c}\text { tumor } \\
\text { incidence }\end{array}$ & $\begin{array}{c}\text { total no. } \\
\text { of tumors }\end{array}$ & $\begin{array}{c}\% \\
\text { inhibitiona }\end{array}$ \\
\hline DMBA & none & 0.1 & $26 / 30$ & 74 & \\
& Se-garlic & 3 & $11 / 30^{\mathrm{b}}$ & $25^{\mathrm{b}}$ & 66 \\
& Se-yeast & 3 & $19 / 30^{\mathrm{c}}$ & $49^{\mathrm{c}}$ & 34 \\
MNU & none & 0.1 & $28 / 30$ & 80 & \\
& Se-garlic & 3 & $10 / 30^{\mathrm{b}}$ & $24^{\mathrm{b}}$ & 70 \\
& Se-yeast & 3 & $20 / 30^{\mathrm{c}}$ & $55^{\mathrm{c}}$ & 31
\end{tabular}

a Calculated based on total tumor yield data. ${ }^{\mathrm{b}} \mathrm{P}<0.05$, compared to the corresponding Se-yeast group. ${ }^{c} \mathrm{P}<0.05$, compared to the corresponding control group.

probably because of the much lower sample number in each category once the data were segregated. Nonetheless, it can be seen that, especially in the Se-garlic group, the reduction in IDP number was more preval ent in the larger-sized lesions. F or example, there were only 7 lesions of $>21$ sections in the Segarlic group as compared to 16 in the Se-yeast group and 24 in the control. The data suggest that (i) selenium chemoprevention is expressed at an early stage of carcinogenesis and (ii) Se-garlic is more active than Se-yeast in suppressing the clonal expansion of these early lesions.

The experiments evaluating the mammary cancer prevention efficacies of Segarlic and Seyeast are presented in Table 4. Both supplements were started immediately after administration of either DMBA or MNU and continued until termination of the study. The data showed the change in tumor incidence and total tumor number as the endpoint. On the basis of these two parameters, our results indicated that Se-garlic was more effective than Se-yeast in mammary cancer protection in both the DMBA and MNU models. The last column of Table 4 shows the percent inhibition calculated from the tumor yield data; Se-garlic produced 66 and $70 \%$ inhibition in the DMBA and MNU experiments, in contrast to only 34 and $31 \%$ inhibition for Seyeast.

\section{DISCUSSION}

In the present study, we found that Se-yeast was only half as active as Se-garlic in our mammary cancer chemoprevention studies, despite the fact that there was a much higher total tissue selenium accumulation with Se-yeast than with Se-garlic. Analytical speciation studies showed that the bulk of the selenium in Se-garlic and Se-yeast is in the form of $\gamma$-glutamyl-Semethylselenocysteine and selenomethionine, respectively. This is the first time $>90 \%$ of the chemical form of selenium was identified and accounted for in a selenium-enriched natural product. We will discuss the interdependence of bi ol ogy and chemistry in sel enium chemoprevention on the basis of the knowledge gained from our past research.

We recently reported that a $1355 \mu \mathrm{g} / \mathrm{g}$ Se garlic sample contains Semethylselenocysteine as the major

\author{
$\mathrm{NH}-\mathrm{CO}-\mathrm{CH}_{2}-\mathrm{CH}_{2}-\mathrm{CH}\left(\mathrm{NH}_{2}\right)-\mathrm{COOH}$ \\ $\mathrm{CH}_{3}-\mathrm{Se}-\mathrm{CH}_{2}-\mathrm{CH}-\mathrm{COOH}$
}

$\gamma$-glutamyl-Se-methylselenocysteine

\section{$\mathrm{CH}_{3}-\mathrm{Se}-\mathrm{CH}_{2}-\mathrm{CH}\left(\mathrm{NH}_{2}\right)-\mathrm{COOH}$}

Se-methylselenocysteine

\section{$\mathrm{CH}_{3}-\mathrm{Se}-\mathrm{CH}_{2}-\mathrm{CH}_{2}-\mathrm{CH}\left(\mathrm{NH}_{2}\right)-\mathrm{COOH}$ \\ Selenomethionine}

Figure 6. Structures of $\gamma$-glutamyl-Semethyl selenocysteine, Semethylselenocysteine, and selenomethionine.

form of selenium (Cai et al., 1995; Bird et al., 1997a), in contrast to the present finding of $\gamma$-glutamyl-Se methylselenocystei ne as the predominant compound in a $296 \mu \mathrm{g} / \mathrm{g}$ Se garlic sample. Our additional studies indicate that garlic samples containing $<300 \mu \mathrm{g} / \mathrm{g}$ Se all produce the $\gamma$-glutamyl derivative as a major storage form for selenium. Both $\gamma$-glutamyl-Semethylselenocysteine and Semethylselenocysteine were previously identified in Astragalus bisulcatus (Nigan and McConnell, 1969). Furthermore, $\gamma$-glutamyl-S-alk(en)ylcysteines are well-known sulfur storage compounds in garlic (Virtanen, 1965; Koch and Lawson, 1996; Block, 1992). Interestingly, some earlier experiments by I $p$ and Lisk (1995) demonstrated that the anticarcinogenic effect of Se-garlic is unlikely to be affected by the degree of selenium enrichment in the garlic sample. Furthermore, the highly enriched and moderately enriched $\mathrm{Se}$ garlic produced similar increases in tissue selenium provided that the total intake of selenium was the same. Given what we know now about the forms of selenium in the 1355 and $296 \mu \mathrm{g} / \mathrm{g}$ Se garlic samples, it would be reasonable to assume that $\gamma$-glutamyl-Semethylselenocysteine serves mainly as a carrier of Semethylselenocysteine. Following ingestion as a dietary constituent, $\gamma$-glutamyl-Se-methylsel enocysteine (Figure 6) is likely to be hydrolyzed by a transpeptidase in the gastrointestinal tract, releasing Se-methylselenocysteine for absorption and systemic delivery to other tissues. We plan to use pure $\gamma$-glutamyl-Se-methylselenocysteine in our future experiments to examine the pharmacokinetics of selenium accumulation and the metabolic disposition of selenium from this molecule.

As shown in Figure 7, Se-methylselenocysteine is metabolized in vivo by a $\beta$-lyase enzyme to methylselenol (Foster et al., 1986; Ganther and Lawrence, 1997). This enzyme is present in a number of tissues including liver, kidney, mammary gland, and intestine (I p et al., 1999). On the basis of our past research experience, any precursor that will generate methylsel enol (or a related monomethylated selenium intermediate) via a similar reaction is more active than selenite or selenomethionine in tumor inhibition (Ganther and Lawrence, 1997; Ip and Ganther, 1992; Ip, 1998). Thus, the facile endogenous production of monomethylated selenium is a critical factor in selenium chemoprevention. This may explain the superior activity of Se-garlic compared to 


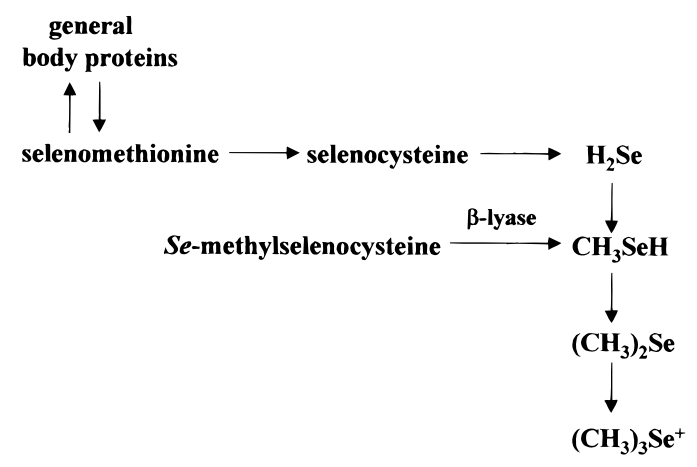

Figure 7. Metabolism of selenomethionine and Se-methylselenocysteine.

Seyeast, because the latter delivers predominantly selenomethionine.

The structures of Semethylsel enocysteine and selenomethionine are very similar to each other (Figure 6). Their respective molecular weights are 182 and 196, the difference being accounted for by an additional methylene carbon in selenomethionine. Despite the similarity in chemical structure, these two selenoamino acids are metabolized very differently (Figure 7). Selenomethionine is known to be incorporated nonspecifically into tissue proteins in place of methionine during protein synthesis, whereas this is not true for Semethylselenocysteine (Sunde, 1990). Total body burden of selenium is therefore consistently higher in rats fed selenomethionine compared to those fed other forms of seleni um (McAdam and Levander, 1987; Whanger and Butler, 1988; I p and Hayes, 1989). Due to its compartmentalization into tissue proteins, sel enomethionine is not as readily available as Semethyl sel enocysteine for further metabolism. As noted above, the efficiency of a selenoamino acid in entering the methylation pathway of selenium metabolism is important in selenium chemoprevention (Ganther and Lawrence, 1997; I $p$ and Ganther, 1992; I p, 1998). In contrast to the $\beta$-lyase-mediated reaction converting Semethylselenocysteine to methylselenol, sel enomethionine is metabolized via the multistep transselenization mechanism to selenocysteine analogous to the methionine transsulfuration mechanism. Sel enocysteine, in turn, is degraded to hydrogen selenide before entering the methylation pathway (I p and Ganther, 1992). The slower rate of generating monomethylated metabol ite from selenomethionine may also in part account for its lower anticarcinogenic activity. A relationship between selenium source and biological activity has also been described by Finley (1998). He found that selenium from high-Se broccoli was less effective in repleting peroxidase activity than selenium from selenite, selenate, or selenomethionine. Furthermore, more selenium from broccoli was excreted in urine of rats than selenium from selenomethionine.

Because the appearance of IDP lesions precedes the development of adenocarcinomas in the mammary gland, their quantitative reduction by sel enium treatment suggests that the primary action of selenium is to inhibit clonal expansion of the carcinogen-initiated cells at an early stage of the disease process. It should be pointed out that, in this study, the size of these lesions is defined operationally by the number of serial histologic sections containing the pathology. Our data indicated that Se-garlic is more potent in suppressing the growth of these premalignant lesions. This finding implies that different selenium compounds may have different efficacies in regulating the proliferation and/ or apoptosis of the early transformed cells. These research questions are presently under investigation.

The purpose of this paper is not to make recommendation of one selenium-enriched product over another for human use. The biological experiments re ported here were conducted in a particular animal model, which has its own share of limitations and confounders. The application of the present sophisticated analytical instrumentation and methodology for selenium speciation has enabled a more informative and coherent approach to be followed than formerly was available to such investigations. The Clark (1996) trial has offered a glimmer of encouragement that significant cancer prevention can be achieved by selenium supplementation. We hope to add to this research database by underscoring that chemistry and biology should go hand in hand in our continuing effort to develop new strategies for selenium intervention of cancer.

\section{ABBREVIATIONS USED}

HPLC, high-performance liquid chromatography; ICP, inductively coupled plasma; MS, mass spectrometry; ESI, electrospray; SIC, single ion chromatogram; IDP, intraductal proliferation lesion; $\mathrm{MNU}$, methyl nitrosourea; DMBA, dimethyl benz[a]anthracene.

\section{ACKNOWLEDGMENT}

We are grateful to Pam Wolfe of the AMC Cancer Research Center, Denver, CO, for her help in statistical analysis.

\section{LITERATURE CITED}

Bird, S. M.; Ge, H.; Uden, P. C.; Tyson, J. F.; Block, E.; Denoyer, E. High-performance liquid chromatography of selenoamino acids and organo selenium compounds. Spe ciation by inductively coupled plasma mass spectrometry. J . Chromatogr. A 1997a, 789, 349-359.

Bird, S. M.; Uden, P. C.; Tyson, J . F.; Block, E.; Denoyer, E. Speciation of selenoamino acids and organoselenium compounds in sel enium-enriched yeast using high-performance liquid chromatography-inductively coupled plasma mass spectrometry. J . Anal. Atom. Spectrom. 1997b, 12, 785788.

Block, E. The organosulfur chemistry of the genus AlliumImplications for organic sulfur chemistry. Angew. Chem., Int. Ed. Engl. 1992, 31, 1135-1178.

Cai, X. J .; Block, E.; Uden, P. C.; Zhang, Z.; Quimby, B. D.; Sullivan, J.J. Allium chemistry: Identification of selenoamino acids in ordinary and selenium-enriched garlic, onion, and broccoli using gas chromatography with atomic emission detection. J . Agric. Food Chem. 1995, 43, 17541757.

Casiot, C.; Vacchina, V.; Chassaigne, H.; Szpunar, J .; PotinGautier, M.; Lobinski, R. An approach to the identification of selenium species in yeast extracts using pneumaticallyassisted electrospray tandem mass spectrometry. Anal. Commun. 1999, 36, 77-80.

Clark, L. C.; Combs, G. F.; Turnbull, B. W.; Slate, E. H.; Chalker, D. K.; Chow, J .; Davis, L. S.; Glover, R. A.; Graham, G. F.; Gross, E. G.; Krongrad, A.; Lesher, J . L.; Park, K.; Sanders, B. B.; Smith, C. L.; Taylor, R. Effects of selenium supplementation for cancer prevention in patients with carcinoma of the skin. J . Am. Med. Assoc. 1996, 276, 1957-1985.

Finley, J. W. The adsorption and tissue distribution of selenium from high-selenium broccoli are different from selenium from sodium selenite, sodium selenate, and sele 
nomethionine as determined in selenium-deficient rats. J . Agric. Food Chem. 1998, 46, 3702-3707.

Foster, S. J .; Kraus, R. J .; Ganther, H. E. The metabol ism of selenomethionine, Se-methylselenocysteine, their selenonium derivatives, and trimethylselenonium in the rat. Arch. Biochem. Biophys. 1986, 251, 77-86.

Ganther, H. E.; Lawrence, J . R. Chemical transformations of sel enium in living organisms. I mproved forms of sel enium for cancer prevention. Tetrahedron 1997, 53, 12299-12310.

Ge, H.; Cai, X.-J .; Tyson, J . F.; U den, P. C.; Denoyer, E.; Block, $\mathrm{E}$. Identification of selenium species in selenium-enriched garlic, onion and broccoli using high-performance ion chromatography with inductively coupled plasma mass spectrometry detection. Anal. Commun. 1996, 33, 279-281.

Horvath, P. M.; Ip, C. Synergistic effect of vitamin E and selenium in chemoprevention of mammary carcinogenesis in rats. Cancer Res. 1983, 43, 5335-5341.

Ip, C. Lessons from basic research in selenium and cancer prevention. J . Nutr. 1998, 128, 1845-1854.

I p, C.; Ganther, H. E. Relationship between the chemical form of selenium and anticarcinogenic activity. In Cancer Chemoprevention; Wattenberg, L., Lipkin, M., Boone, C. W., Kelloff, G. J ., Eds.; CRC Press: Boca Raton, FL, 1992; pp 479-488.

Ip, C.; Hayes, C. Tissue selenium levels in selenium-supplemented rats and their relevance in mammary cancer protection. Carcinogenesis 1989, 10, 921-925.

I p, C.; Lisk, D. J . Enrichment of selenium in allium vegetables for cancer prevention. Carcinogenesis 1994, 15, 1881-1885.

Ip, C.; Lisk, D. J. Efficacy of cancer prevention by high selenium-garlic is primarily dependent on the action of selenium. Carcinogenesis 1995, 16, 2649-2652.

I p, C.; Lisk, D. J . Modulation of phasel and phase II xenobiotic metabolizing enzymes by selenium-enriched garlic in rats. Nutr. Cancer 1997, 28, 184-188.

I p, C.; Lisk, D. J .; Stoewsand, G. S. Mammary cancer prevention by regular garlic and selenium enriched garlic. Nutr. Cancer 1992, 17, 279-286.

Ip, C.; Lisk, D. J .; Thompson, H. Selenium-enriched garlic inhibits the early stage but not the late stage of mammary carcinogenesis. Carcinogenesis 1996, 17, 1979-1982.

Ip, C.; Zhu, Z.; Thompson, H. J .; Lisk, D.; Ganther, H. E. Chemoprevention of mammary cancer with Se-allylselenocysteine and other selenoamino acids in the rat. Anticancer Res. 1999, 19, 2875-2880.

Koch, H. P.; Lawson, L. D. Garlic. TheScienceand Therapeutic Applications of Allium sativum L. and Related Species; William and Wilkens: Baltimore, MD, 1996.

Kotrebai, M.; Bird, S. M.; Tyson, J . F.; Block, E .; Uden, P. C. Characterization of selenium species in biological extracts by enhanced ion-pair liquid chromatography with inductively coupled plasma- and electrospray ionization-mass spectrometric detection. Spectrochim. Acta B 1999, 54, 1573-1591.

McAdam, P. A.; Levander, O. A. Chronic toxicity and retention of dietary selenium fed to rats as D- or L-selenomethionine, selenite, or selenate. Nutr. Res. 1987, 7, 601-610.
McCullagh, P.; Nelder, J . A. Generalized Linear Models, 2nd ed.; Chapman and Hall: London, U.K., 1989.

Morris, V. C.; Levander, O. A. Selenium content of foods. J . Nutr. 1970, 100, 1383-1388.

Nigan, S. N.; McConnell, W. B. Seleno amino compounds from Astragalus bisculcatus. I solation and identification of $\gamma$-Lgl utamyl-Se-methylseleno-L-cysteine and SemethylselenoL-cysteine. Biochim. Biophys. Acta 1969, 192, 185-190.

Olson, O. E.; Palmer, I. S.; Carey, E. E. Modification of the official fluorometric method for selenium in plants. J . Assoc. Offic. Anal. Chem. 1975, 58, 117-121.

Report of the American Institute of Nutrition Ad Hoc Committee on the Standards for Nutritional Studies. J . Nutr. 1977, 107, 1340-1348.

Russo, J.; Tay, L. K.; Russo, I. H. Differentiation of the mammary gland and susceptibility to carcinogenesis. Breast Cancer Res. Treat. 1982, 2, 5-73.

Shrift, A. Metabolism of selenium by plants and microorganisms. In Organic Selenium Compounds: Their Chemistry and Biology; Klayman, D. K., Gunther, W. W. H., Eds.; Wiley-Interscience: New York, 1973; pp 763-814.

Sunde, R. Molecular biology of selenoproteins. Annu. Rev. Nutr. 1990, 10, 451-474.

Uden, P. C.; Bird, S. M.; Kotrebai, M.; Nolibos, P.; Tyson, J . F.; Block, E.; Denoyer, E. Analytical selenoamino acid studies by chromatography with interfaced atomic mass spectrometry and atomic emission spectral detection. Fre senius' J. Anal. Chem. 1998, 362, 447-456.

Virtanen, A. I. Studies on organic sulfur compounds and other labile substances in plants. Phytochemistry 1965, 4, 207228.

Wattenberg, L. W. Chemoprevention of cancer by naturally occurring and synthetic compounds. In Cancer Chemopre vention; Wattenberg, L., Lipkin, M., Boone, C. W., Kell off, G. J ., Eds.; CRC Press: Boca Raton, FL, 1992; pp 19-39.

Whanger, P. D.; Butler, J. A. Effects of various dietary levels of selenium as selenite or selenomethionine on tissue selenium levels and glutathione peroxidase activity in rats. J. Nutr. 1988, 118, 846-852.

Received for review J anuary 7, 2000. Revised manuscript received March 30, 2000. Accepted April 4, 2000. This work was supported by Grants CA45164 (C.I., E.B., P.C.U.) and CA27706 (C.I .) from the National Cancer Institute, by Roswell Park Cancer Institute Core Grant CA16056, by National Science F oundation Grants CHE 96-28774 and CHE 99-06566 (E.B.), and by NRI Competitive Grants Program/USDA Grant 96-355003351 (E.B.). We thank the Schering Plough Research Institute for a research fellowship (M.K.).

J F 000051F 